\title{
Periocular migration of hard contact lenses
}

\author{
T J Roberts-Harry, C C Davey, J D Jagger
}

\begin{abstract}
Six cases are presented in which hard contact lenses have migrated into the periocular soft tissues, four into the eyelid, one into the orbit and one which spontaneously reappeared on the cornea 12 years after the patient had last worn contact lenses. Some possible mechanisms of this phenomenon and a review of the literature are presented.
\end{abstract}

Ophthalmology, Royal

Free Hospital, Pond

Street, Hampstead,

London NW3 2QG

T J Roberts-Harry

C C Davey

J D Jagger

Correspondence to:

T J Roberts-Harry.

Accepted for publication 30 May 1991

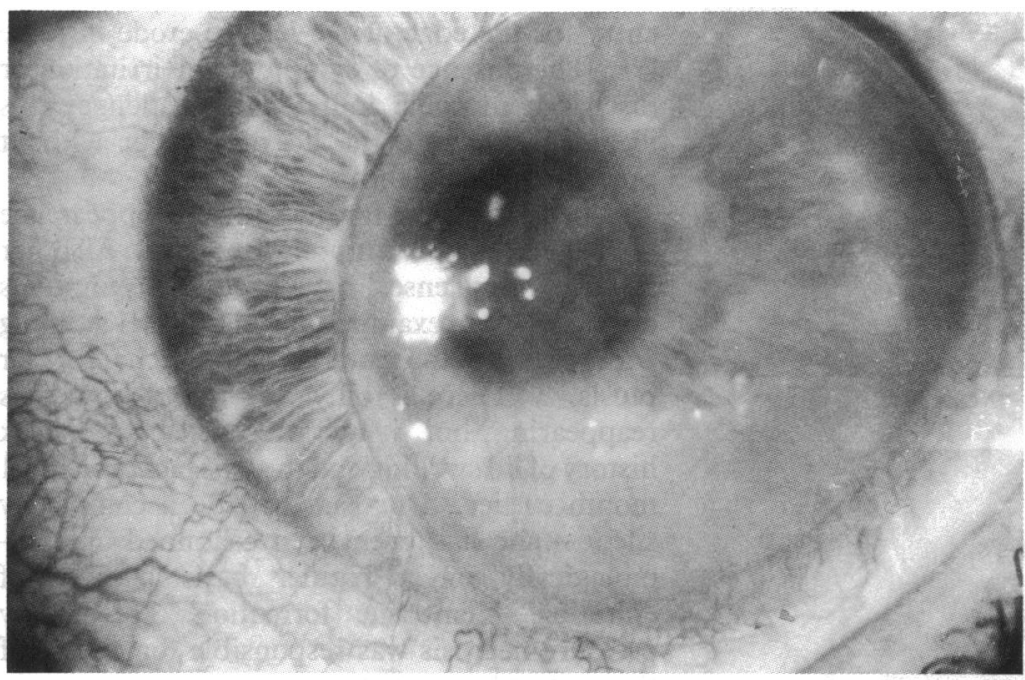

Figure 1 Case 1.

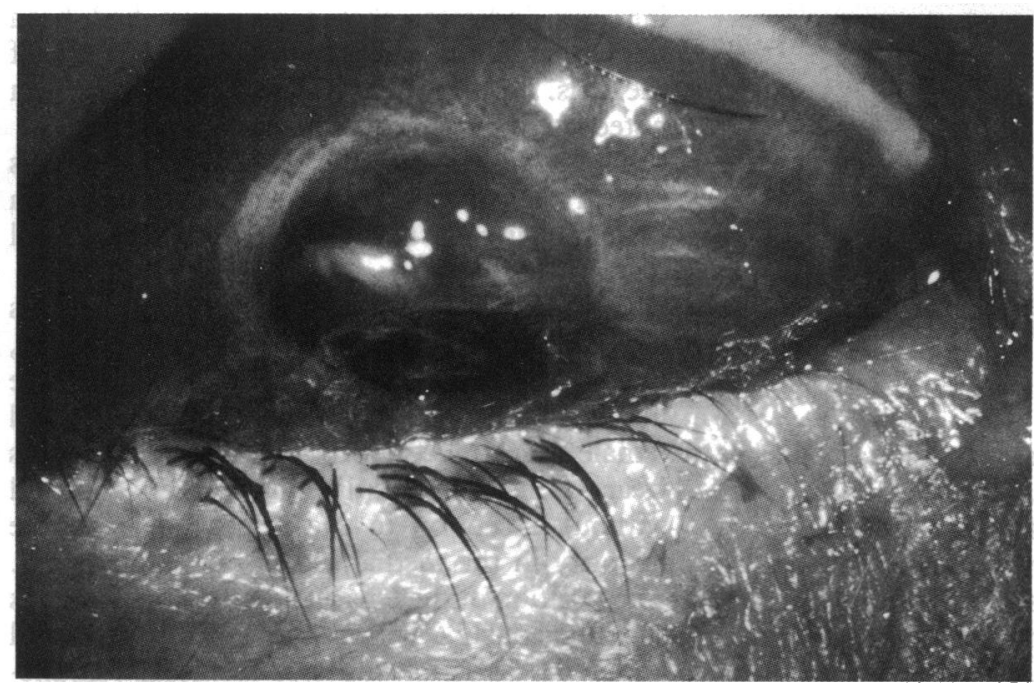

Figure 2 Case 3.

\section{Case reports}

\section{CASE 1}

A 70-year-old woman presented with a 2 hour history of painful sudden loss of vision in her right eye. Visual acuity was at the level of counting fingers at 2 metres. The eye was injected, photophobic, and watering. An encrusted hard contact lens was present on the cornea (Fig 1). Visual acuity improved to $6 / 12$ and her symptoms resolved immediately once the lens was removed. In the past she had worn hard lenses and lost them on a number of occasions. She had last worn them 12 years before and in the interim had been symptom free. Eversion of the eyelid failed to reveal the site of emergence of the lens, but she was unable to tolerate double lid eversion. Electron microscopy of the lens showed it to be encased in a $200 \mu \mathrm{m}$ thick layer of an amorphous deposit.

\section{CASE 2}

A 26-year-old woman presented with a slowly enlarging swelling, otherwise asymptomatic, of 6 months' duration in the left upper lid. She had lost a hard contact lens from her left eye some months before onset of the lid mass. A round, firm, non-tender swelling was evident medially within the tarsal plate. Lid eversion revealed an elevated disc of pale scar tissue on the subtarsal aspect of the lid. When the 'chalazion' was incised a hard lens was found under a thin layer of fibrous tissue. The lid returned to normal 2 weeks after removal of the lens.

CASE 3

A 56-year-old man attended complaining of a tender, swollen right upper lid for 3 days. On everting the lid a perfectly circular ring covered with conjunctiva was seen (Fig 2). A hard lens was removed following exploration of the lesion. The patient admitted having lost the lens 2 years earlier but in the meantime had been completely asymptomatic.

\section{CASE 4}

A 25-year-old woman gave a 3-month history of a slowly enlarging painless lump at the medial aspect of her left upper lid. A firm, smooth, nontender mass was palpable above the tarsal plate in the anterior orbit. Fine needle aspiration biopsy was attempted and it then became apparent that the lesion was hard. Exploration revealed an encysted hard contact lens deep to the orbital septum. Both cyst and lens were removed with resolution of symptoms in 3 weeks. Histologically the cyst wall consisted of chronically inflamed conjunctiva. 


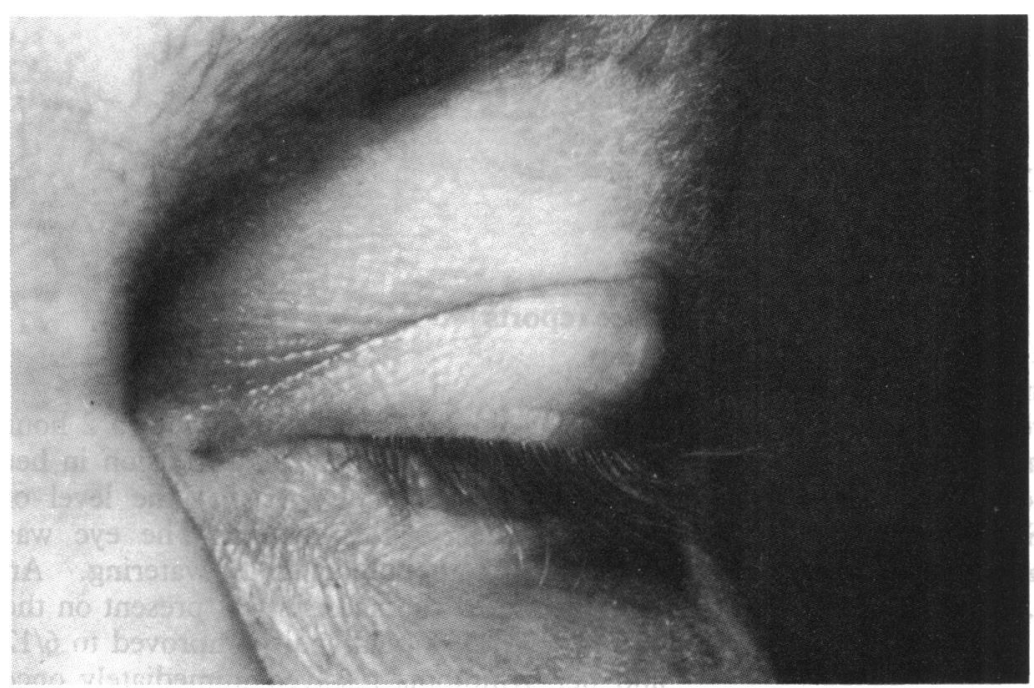

Figure 3 Case 5.

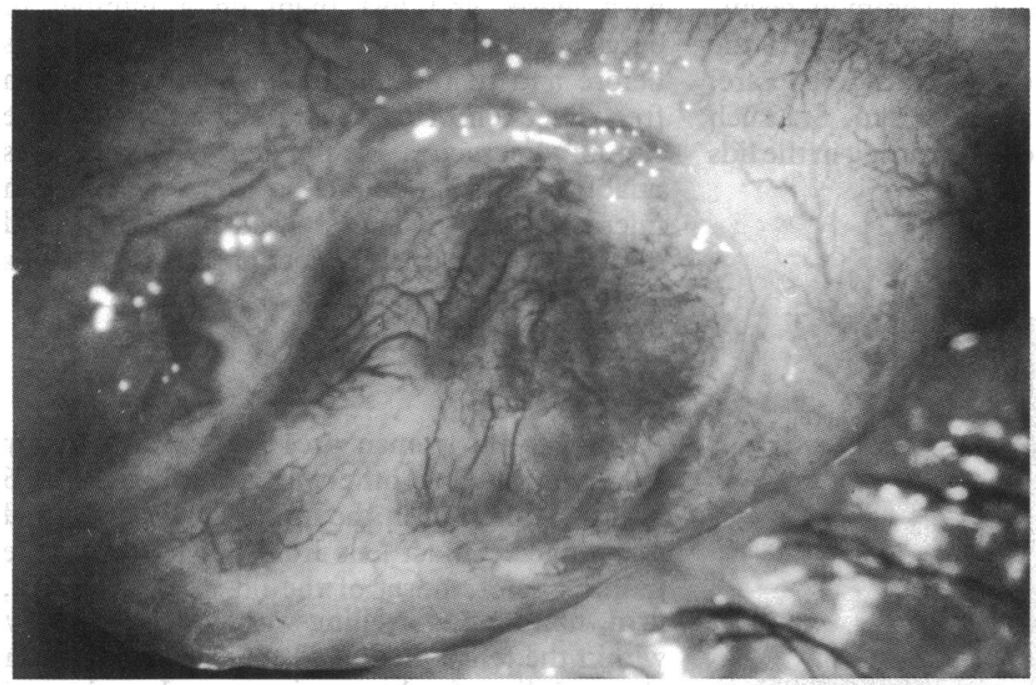

Figure 4 Case 5-lid everted.

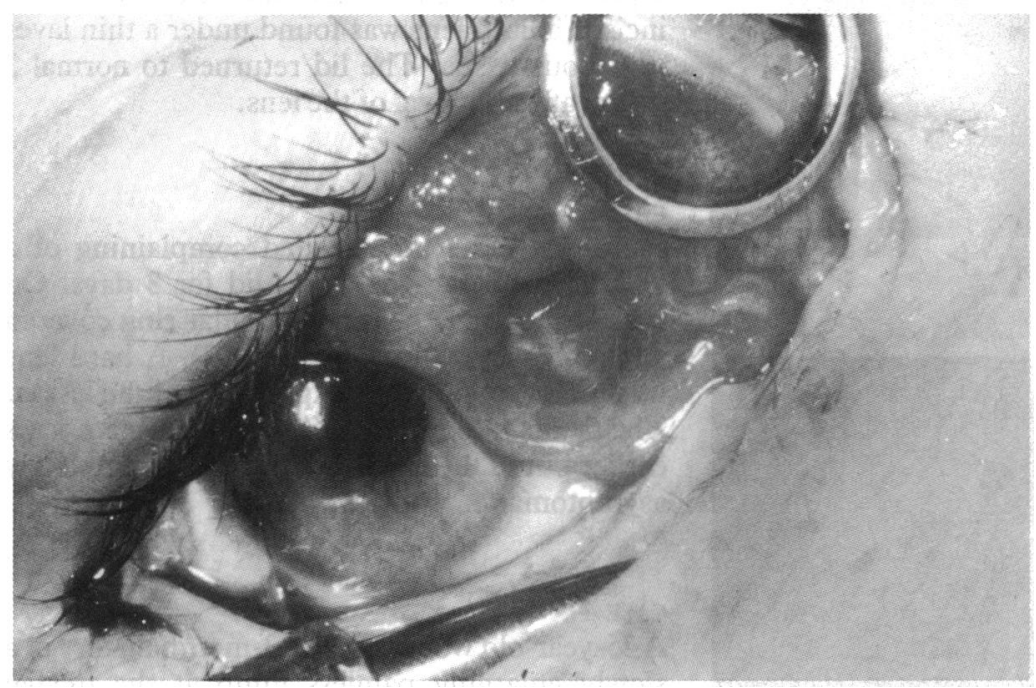

Figure 5 Case 6.

CASE 5

A young man noted a painless swelling in his left upper lid of several weeks' duration (Fig 3). An elevated, vascularised mass involving the tarsal plate was visible on lid eversion (Fig 4). Because of the rapid rate of onset and the aggressive appearance of the lesion, a meibomian gland carcinoma was suspected. At surgery a hard lens was found beneath the subtarsal conjunctiva.
Removal of the lens was followed by full recovery within a few weeks.

CASE 6

A 19-year-old woman presented with an inflamed swelling medially in the right upper lid. A hard lens was discovered partly embedded in the subtarsal surface of the lid, with an elevated ring of hypertrophic conjunctiva around its circumference (Fig 5). She made a full recovery within 3 weeks of the lens being removed.

\section{Discussion}

The loss of a lens is a common problem among contact lens wearers. Usually the lens falls from the eye. Rarely, hard lenses may become embedded in the soft tissues around the eye. One possible explanation for this is that if the lens is displaced into the upper fornix the rim may engage the upper border of the tarsal plate and become trapped - the 'upper fornix trap'. 'The action of the lid combined with pressure necrosis may lead to erosion of the lens into the adjacent tissues. A second theory suggests that the action of the upper lid on the displaced lens induces local abscess formation in the palpebral conjunctiva. Rupture of the abscess allows a point of entry for the edge of the lens to erode into the lid. ${ }^{2}$ The absence of symptoms of irritation or discharge in some individuals challenges this idea. Erosion into the lid may occur without preceding abscess formation. ${ }^{3}$

Case 1 is unusual for the sudden reappearance of the lens after 12 symptom-free years. All other reported 'lost lenses' have produced symptoms or signs, for example localised lid swelling with or without tenderness, ${ }^{2-9}$ discharge $^{4-6}$ or ptosis. ${ }^{1011}$ There is only one report of a lens reappearing, but, it was preceded by a 1-week history of lid swelling and the lens had been lost 1 month earlier. ${ }^{6}$ Our case had been completely silent - she had even been examined ophthalmologically on a regular basis because of epiretinal membrane formation. Presumably pressure necrosis was responsible for release of the contact lens onto the cornea.

Case 4 is the second reported case of a hard lens being found in the orbit. ${ }^{12}$ The surrounding cyst indicates that conjunctiva had been implanted into the orbit by the advancing edge of the lens. Epithelial lined cysts have also been noted surrounding contact lenses in the lids. ${ }^{37}$

The appearance of the lid lesion in case 6 is typical of a hard lens buried in the lid - an elevated ring of tissue surrounding a central crater..$^{45912}$

Including those featured here, 21 hard lenses have been reported embedded in the upper lid, two in the orbit and two that extruded from the lid. The majority of patients were young and female reflecting the prevalence of contact lens wear. Lenses in the lids have been confined without exception to the upper lid, with the majority in the medial aspect of the upper lid. The position of the lens within the lid also varies subcutaneously, ${ }^{8}$ within the tarsal plate, ${ }^{6}$ and under the tarsal or superior forniceal conjunctiva. $^{+579-12}$ 
$X$ rays have been used in an effort to diagnose these unusual unidentified lesions, but it is not surprising that lenses cannot be detected radiologically..$^{5710}$ Because of the big acoustic impedance mismatch between biological tissue and polymethylmethacrylate, hard lenses should be detectable on ultrasonography. ${ }^{12}$

It has been suggested that patients with hard lenses buried in their lids fall into two groups, ${ }^{3}$ one in which there is a long time lapse (56 months or more) between loss of a lens and its retrieval, who have no mucopurulent discharge, and a second group of shorter duration that develop conjunctivitis. We feel that the difference in time span may merely reflect that patients who are in discomfort may present earlier than those with a silent lid swelling.

Several of our colleagues have commented on cases of lost contact lenses that have not been reported in the literature. This raises the suggestion that embedding of hard contact lenses in the periocular tissues is not in fact rare, merely uncommon, regarded as a novelty and left unreported.

\section{Conclusion}

Migration of hard contact lenses into the periocular soft tissues is a seemingly rare occurrence. Six cases are described, four of lenses embedded in the upper lids, one in the orbit and one extruding onto the cornea after being lost for 12 years. Lenses erode into the lid due to dynamic action of the lid, with or without local abscess formation. We suspect that this phenomenon is not particularly unusual but remains largely unreported and should be considered in the differential diagnosis of lid lesions in contact lens wearers.

We thank Mr J R O Collin and Mr R Downes for allowing us to report case 5 and $\mathrm{Mr} J$ Dart for the photograph of case 6 .

1 Bock RH. The upper fornix trap. Br $\mathcal{F}$ Ophthalmol 1971; 55: 784

2 Michaels DD, Zugsmith GS. An unusual contact lens complication. Am $\mathcal{F}$ Ophthalmol 1963; 55: 1057.

3 Jones D, Livesey S, Wilkins P. Hard contact lens migration into the upper lid - an unexpected lid lump. Brf Ophthalmol 1987; 5: 368-70

4 Jones D, Hanan HM. Embedding of an inverted hard contact lens. Am F Optom Physiol Opt 1987; 64: 879-80.

5 Green WR. An embedded (lost) contact lens. Arch Ophthalmol 1963; 69: 23-4.

6 Sebag J, Albert DM. Pseudochalazion of the upper lid due to contact lens embedding - case reports and literature review. Ophthalmic Surg 1982; 13: 634-6.

7 Older JJ. Encysted contact lens presenting as an eyelid mass. Ann Ophthalmol 1979; 11: 1393-4.

8 Brinkley JR, Zappia RJ. An eyelid tumour caused by a migrated hard contact lens. Ophthalmic Surg 1980; 11: migrated

9 Long JC. Retention of contact lens in upper fornix. $A m \mathcal{F}$ Ophthalmol 1963; 56: 309.

10 Shenken E. Traumatic dislocation of a contact lens into the eye lid. Can Med Assoc F 1969; 101: 295

11 Yassin JO, White RH, Shannon GH. Blepharoptosis as a complication of contact lens migration. Am $\mathcal{F}$ Ophthalmol 1971; 72: 536-7.

12 Nicolitz E, Flanagan JC. Orbital mass as a complication of contact lens wear. Arch Ophthalmol 1978; 96: 2238-9. 